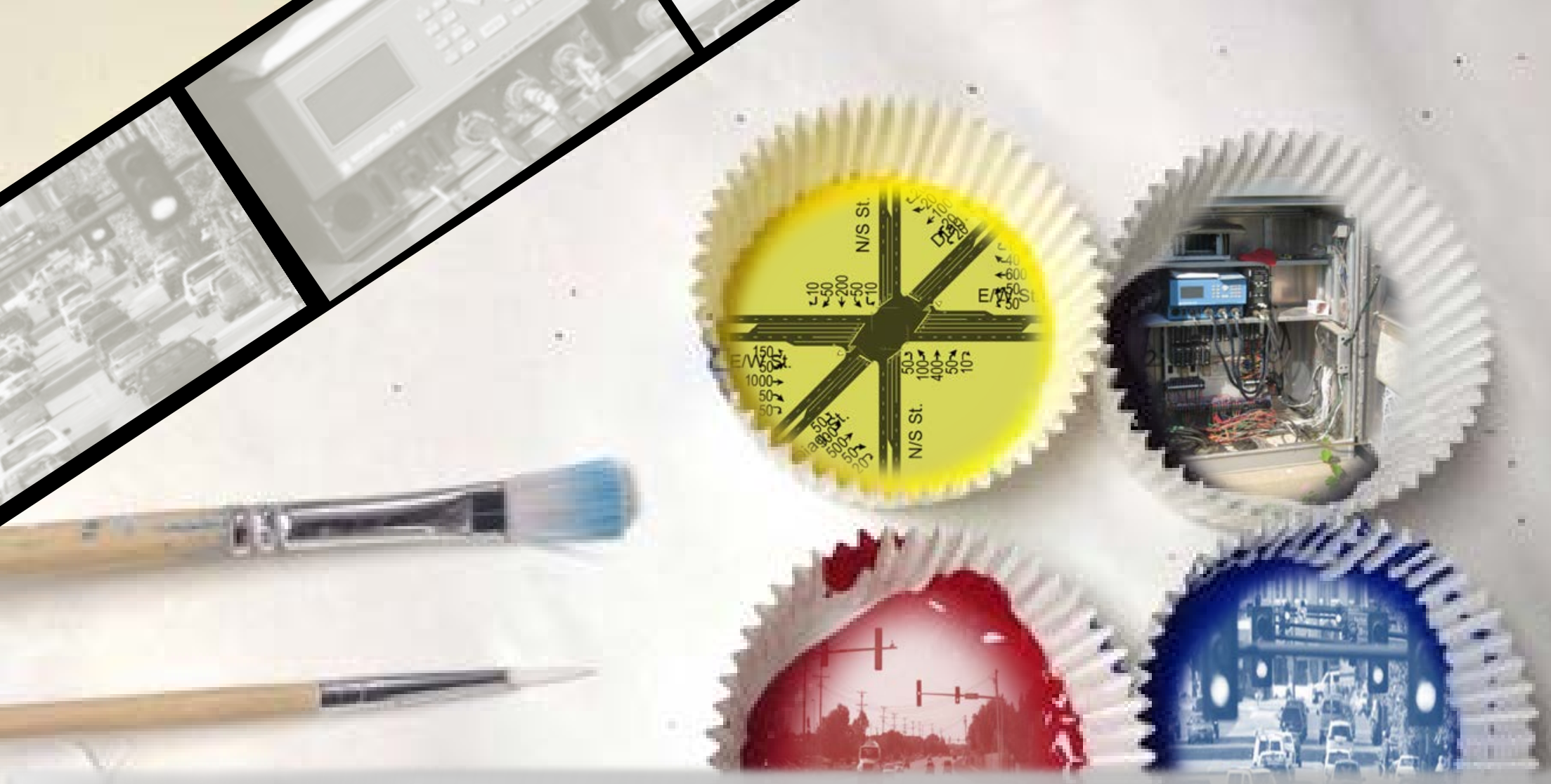

\title{
Lessons Learned from ASCT and Systems Engineering
}

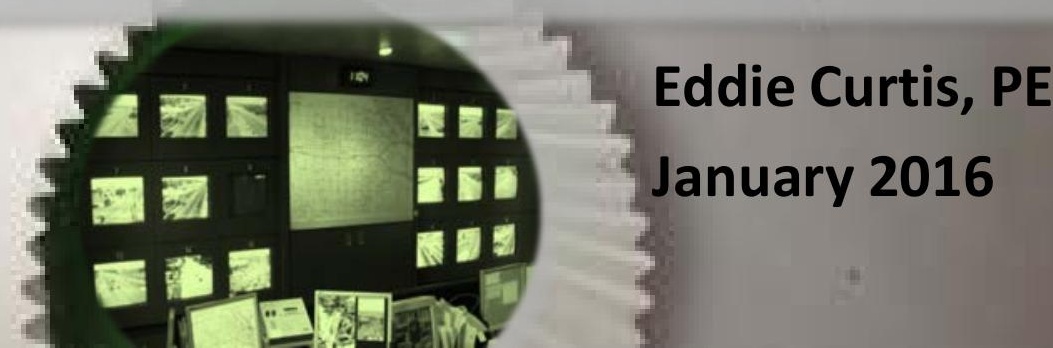




\section{Opening Up}

- Technology Deployment Life

Cycle

- Research

- Technology Development

- People (Risk Tolerance)

- Implementation

- Systematic Process 


\section{Context}

- Federal Reauthorizations (1991 - 2012) Funding Eligibility for operations and maintenance Expanding.

- Rule 940 (ITS Architecture / Systems Engineering)

- Influence of Metropolitan Planning Organizations

Growing

- Traffic Signal Programs Lack Resources
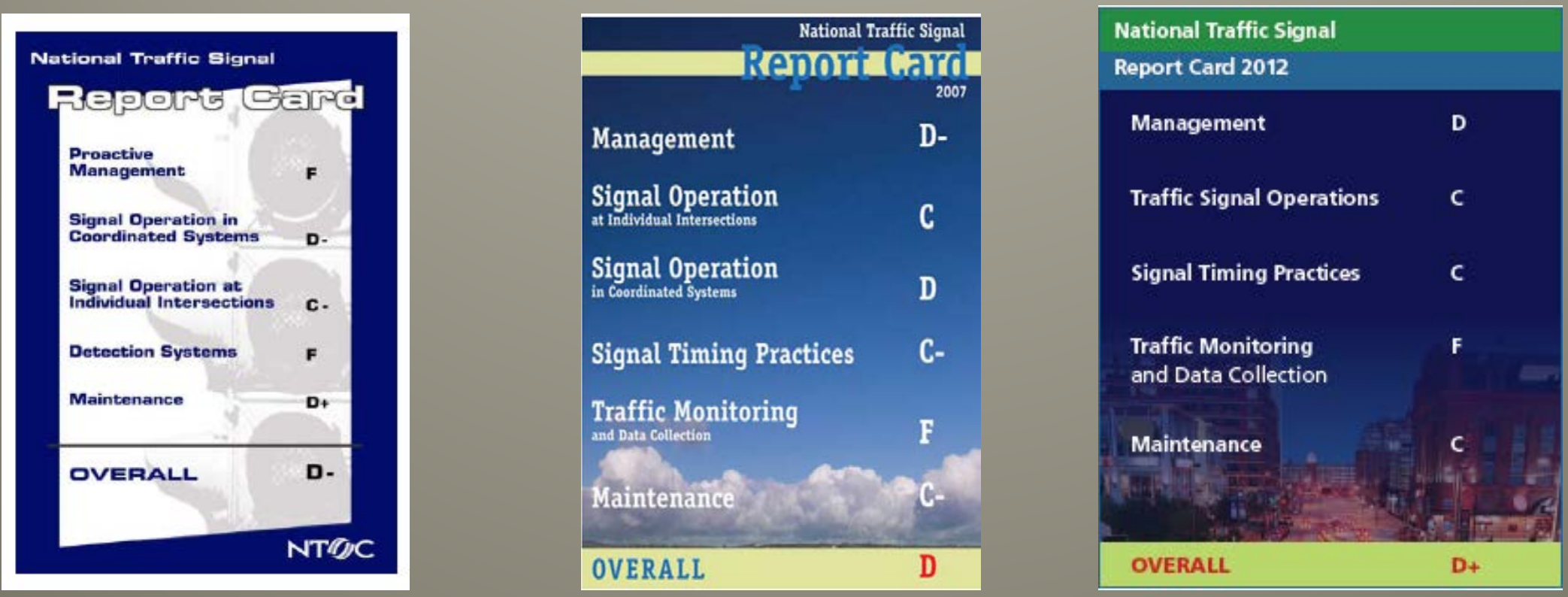


\section{Complex Environment}

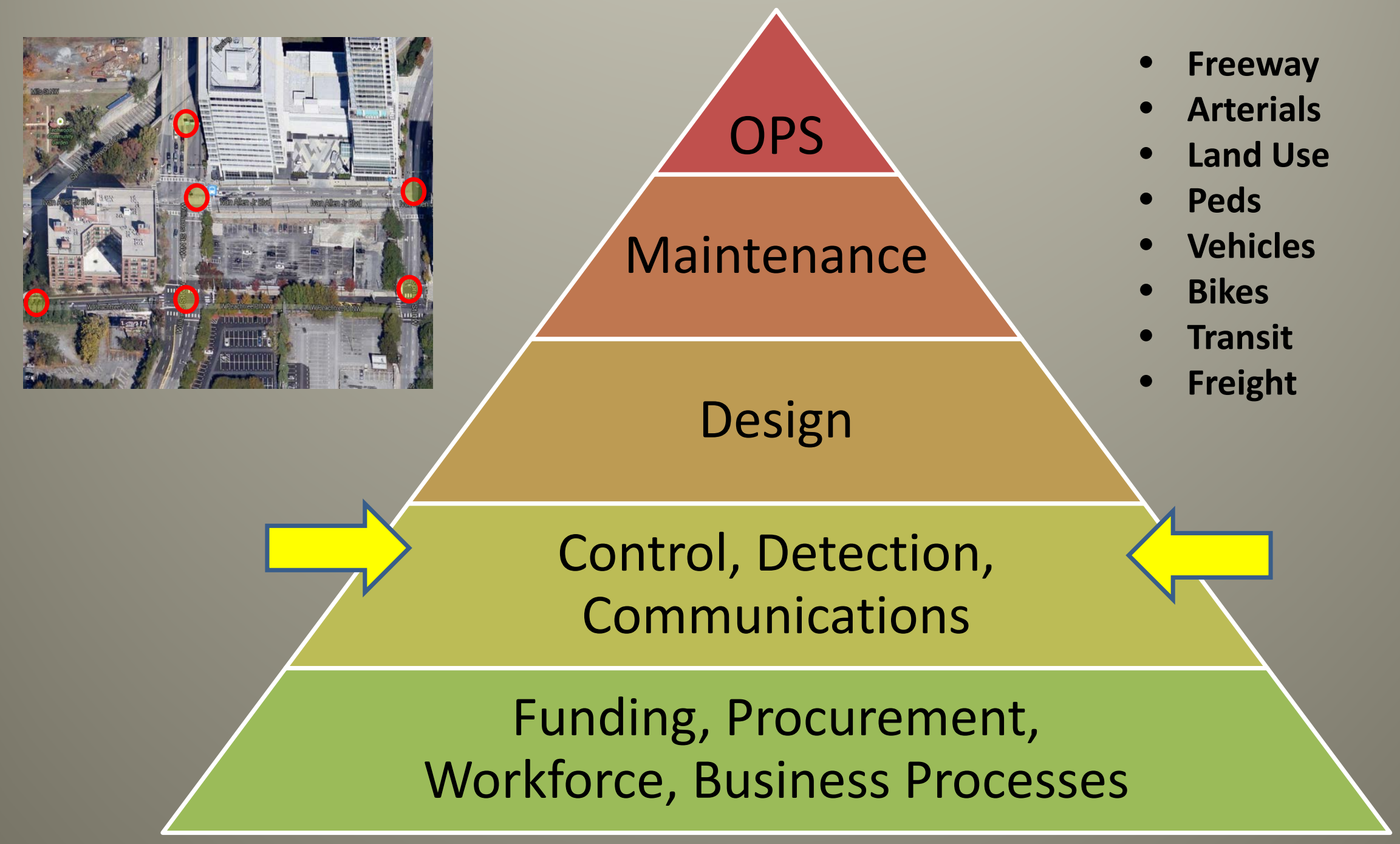




\section{Project Development / Funding}

Process Not Well Understood

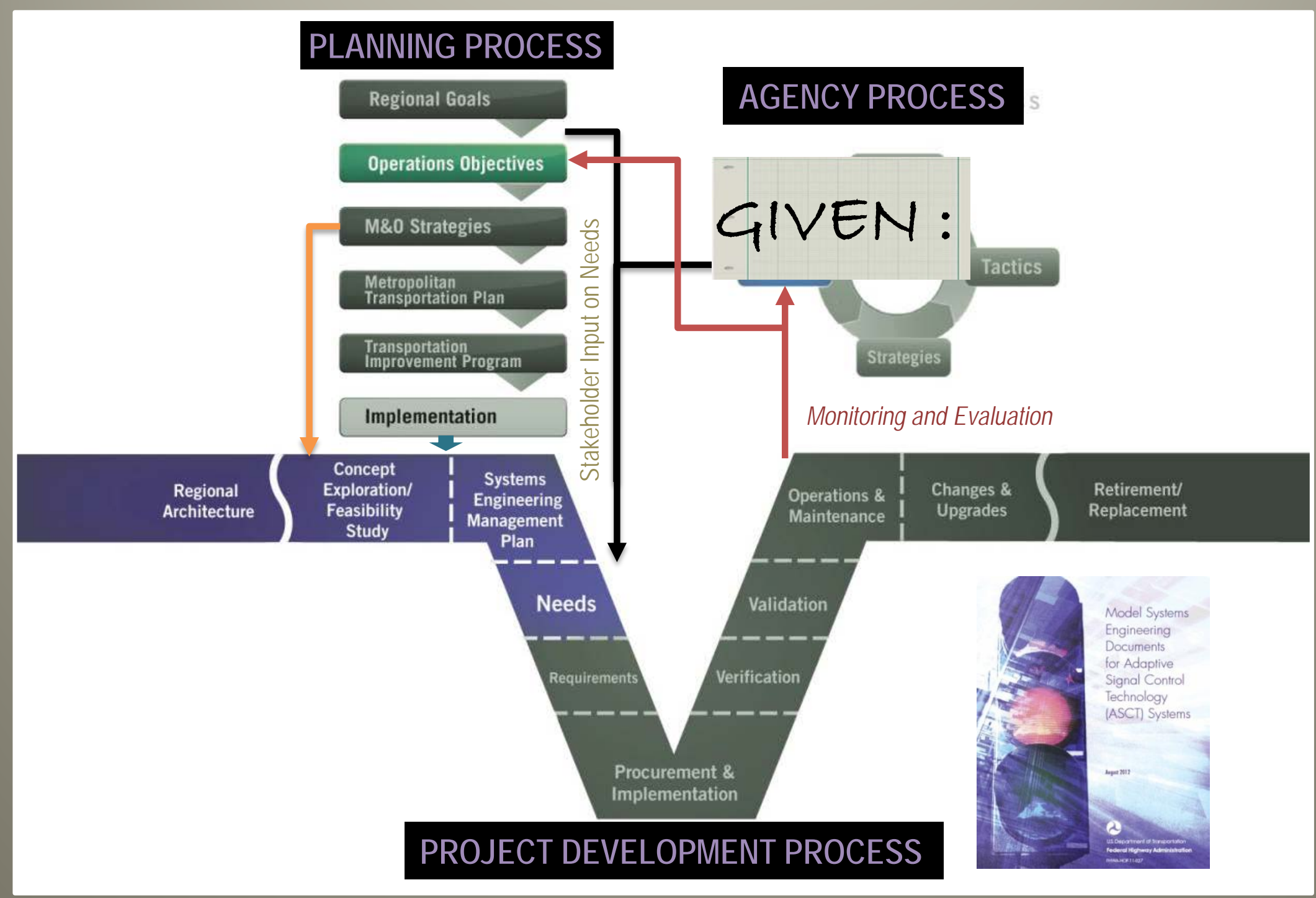




\section{Conceptual Framework (G.O.S.T)}

\section{Goal}

\section{Objective}

Strategy

Tactic
What we are trying to achieve

What needs to be done to achieve the goal

Capabilities put in place to achieve the Objective

Specific methods to achieve the Strategy 


\section{Research Focus}

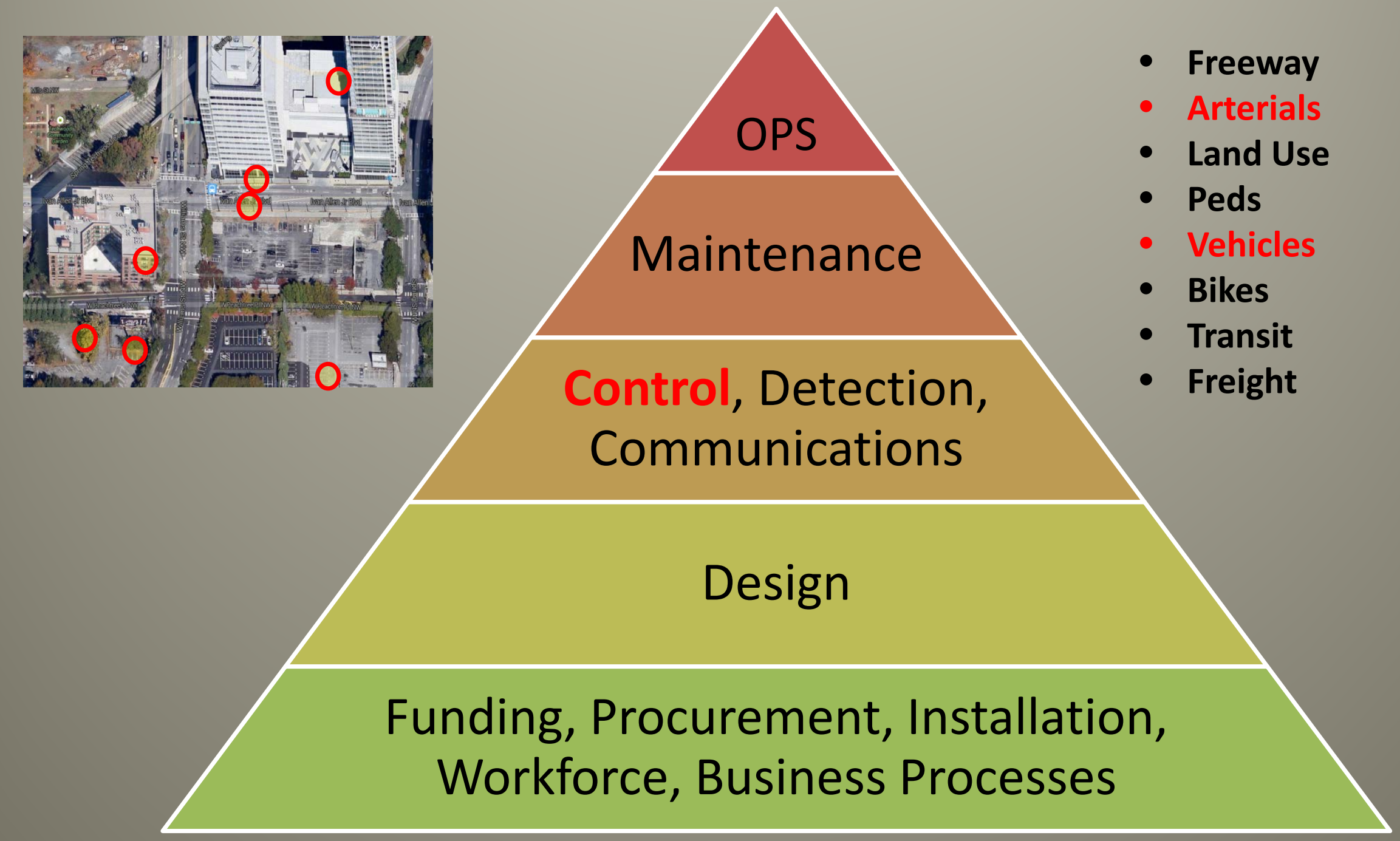




\section{Research Problem}

- Variability in traffic demand reduces the effectiveness of static signal timing plans.

- More TOD Plans,

- Delay Optimization,

- Fine Tuning

- A process is needed to match signal timing plans to traffic patterns to improve efficiency.

- Traffic Responsive

- Transition time between plans reduces effectiveness

- Minimize Transition Time 


\section{Are We Working on the Right Problem?}

GIVEN: Signal Timing Plans (cycle, split, offset) are not keeping pace with variability in demand.

Capabilities put in place to achieve the Objective

Tactic

Specific methods to achieve the Strategy 


\section{Adaptive Signal Control - Research}

- ASC introduced in late 80s

- Split, Cycle, Offset, Optimization, Technique (SCOOT)

- Sydney Coordinated Adaptive Traffic System (SCATS)

- Optimized Policies for Adaptive Control (OPAC)

- Real-Time Traffic Adaptive Control System (RT-TRACS)

- Real Time Hierarchal Optimized Distributed and Effective System (RHODES) 


\section{Field Demonstration Test}

- Significant reductions in Delay, Fuel Consumption \& Emissions

- Requires non-standard local control

- Algorithms are complex

- Extensive detection requirements

- Robust communications

- Expensive to Implement, Operate and Maintain

- Requires active monitoring and calibration 


\section{Shifting to Technology Deployment}

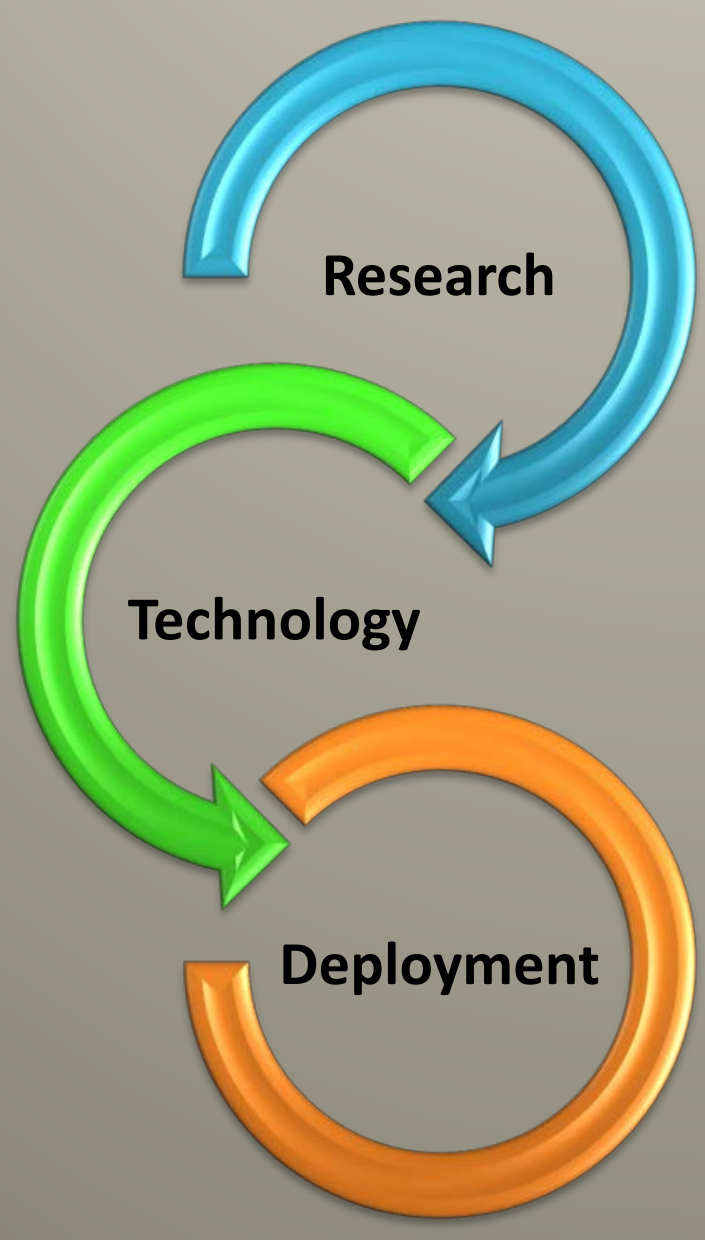

Problem Statement

- Reduce Complexity

- Minimize Detection

- Low Bandwidth Communication

- Utilize Existing Control

\section{Technology}

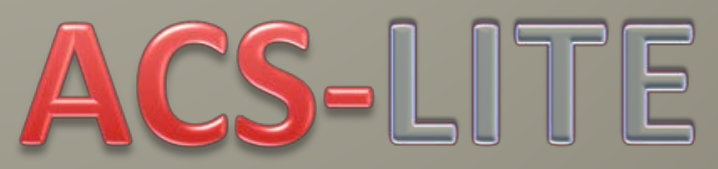

\section{Features}

- NTCIP

- Econolite / Peek / Siemens / McCain

- Low Bandwidth Communication

- Existing Detection

- Spilt and Offset Tuning 


\section{People}

Diffusion of Innovation

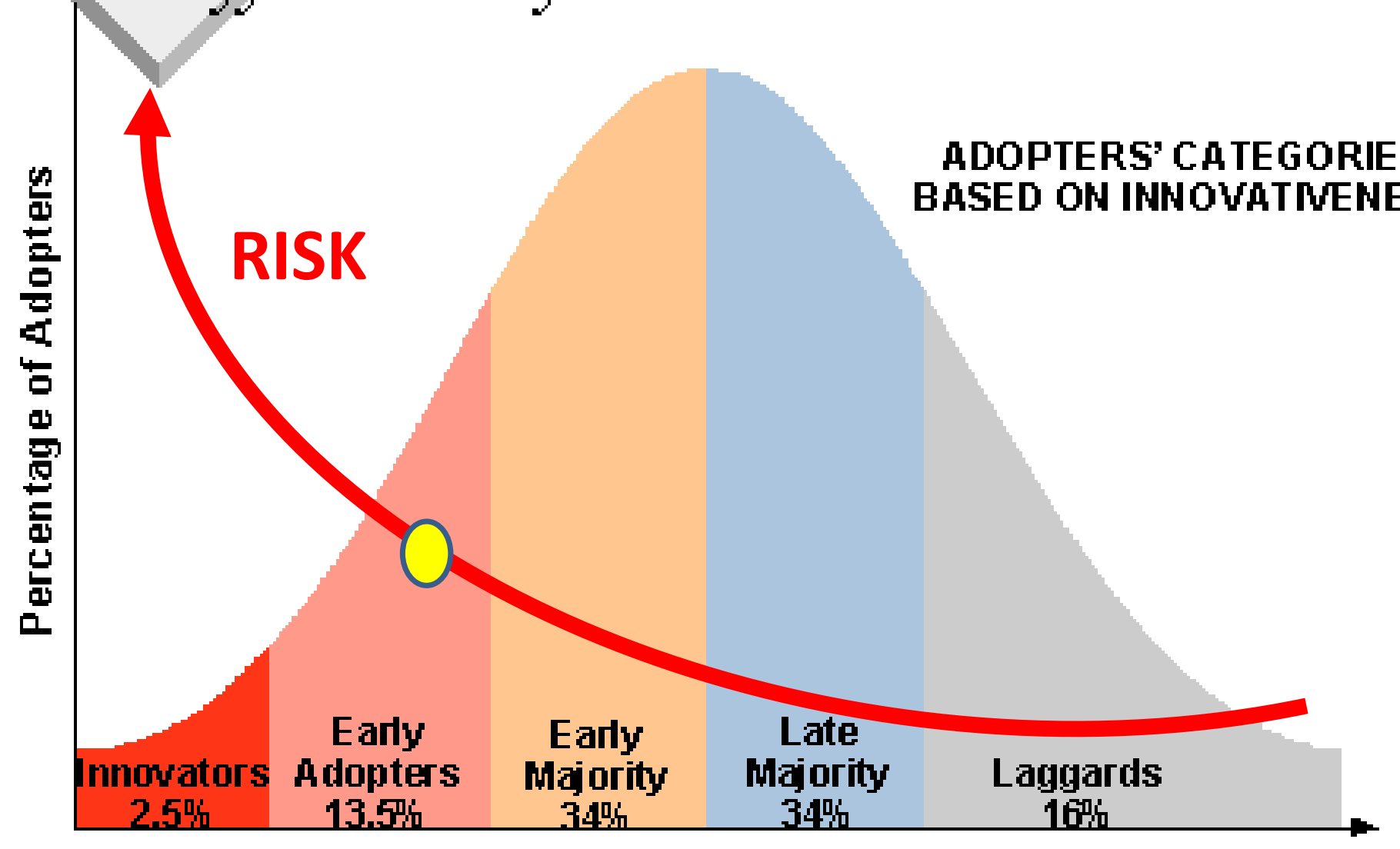

https://suzannehawkes.files.wordpress.com/2007/02/social-innovation.gif 


\section{Deployment 1991 - 2005}

- Research

- Field Operational Test

- Conditions match functional objectives

- No Systems Engineering

- Evaluations

- Organizational issues not considered

- Skilled Staff

- Procurement - Sole Source

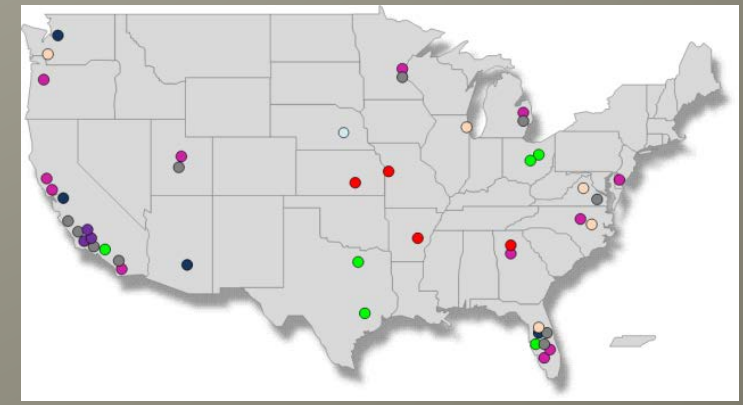




\section{Technology 2006 - 2009}

- FHWA Active Promotion of ACS-Lite

- Econolite

- Siemens

- Peek

- McCain

- Naztec

- NW Signal

- New Products

- InSync / SynchroGreen / QuicTrac.....

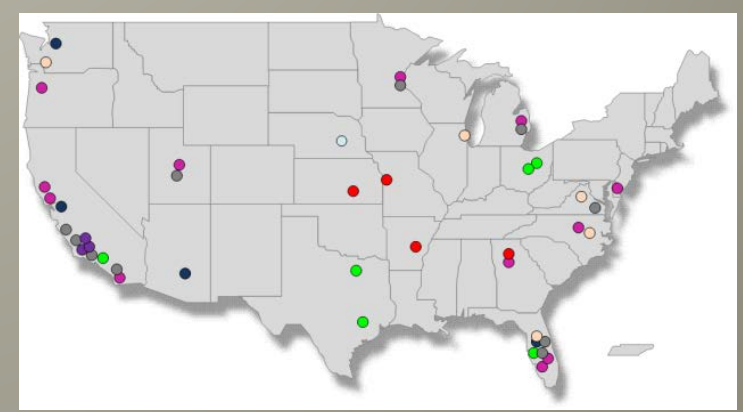

- Other Systems Under Development

- Less than $1 \%$ of all signals equipped with ASCT

- Traffic Responsive is Ubiquitous 


\section{Every Day Counts Initiative 2010 - 2012}

Goal: Mainstream the use of ASCT.

\section{Barriers:}

- Uncertainty about benefits,

- Cost,

- Complexity

- Clear understanding of operation and maintenance requirements

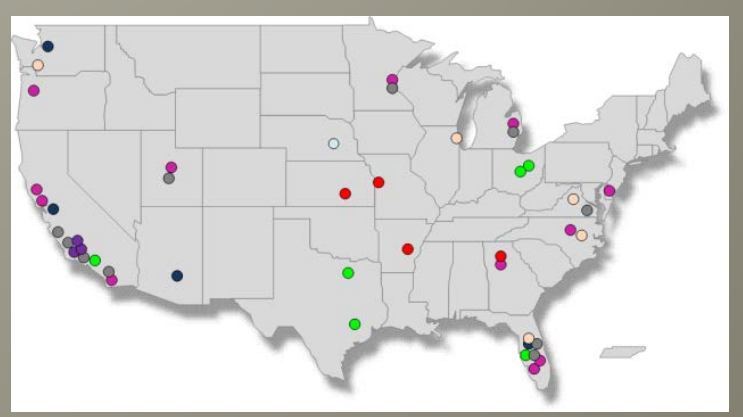




\section{Implementation Approach}

Mission: Provide tools to address risk, characterize ASCT as a strategy to improve operations.

Objective 1: ASCT/Tools will be used by 40 agencies to guide planning and implementation.

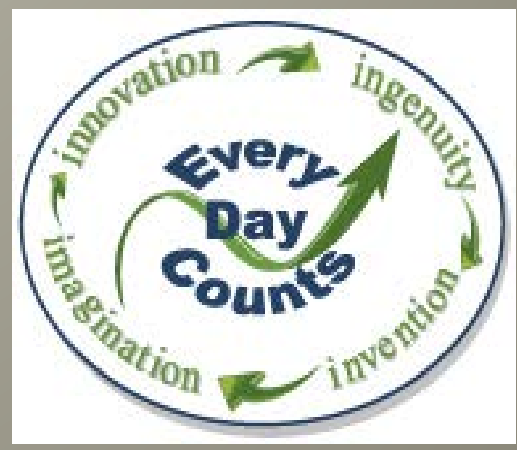

Objective 2: Develop Performance Measures, data needs and methodology to support evaluation of ASCT. 


\section{Systems Engineering Process}

\section{- Systems Engineering Guidebook}

$\begin{array}{cc}\text { Needs } & \text { Concept } \\ \text { Assessment } & \text { Selection }\end{array}$

Project
Planning

Systems

Engineering

Management

Planning

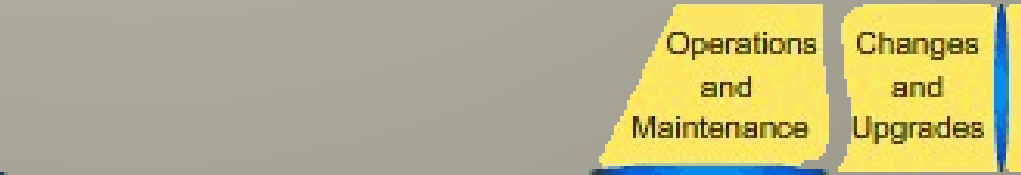

Retirement /

Replacement

Concept of
Operations

System

Requirements

High-Level

Design

Subsystem

Requirements

Detailed

Design

System

Validation

Initial Deployment

System

Venfication

System

Integration

Subsystem

Verification

Subsystem

Integration

Software Coding

Hardare Fabrication 


\section{Systems Engineering Process}

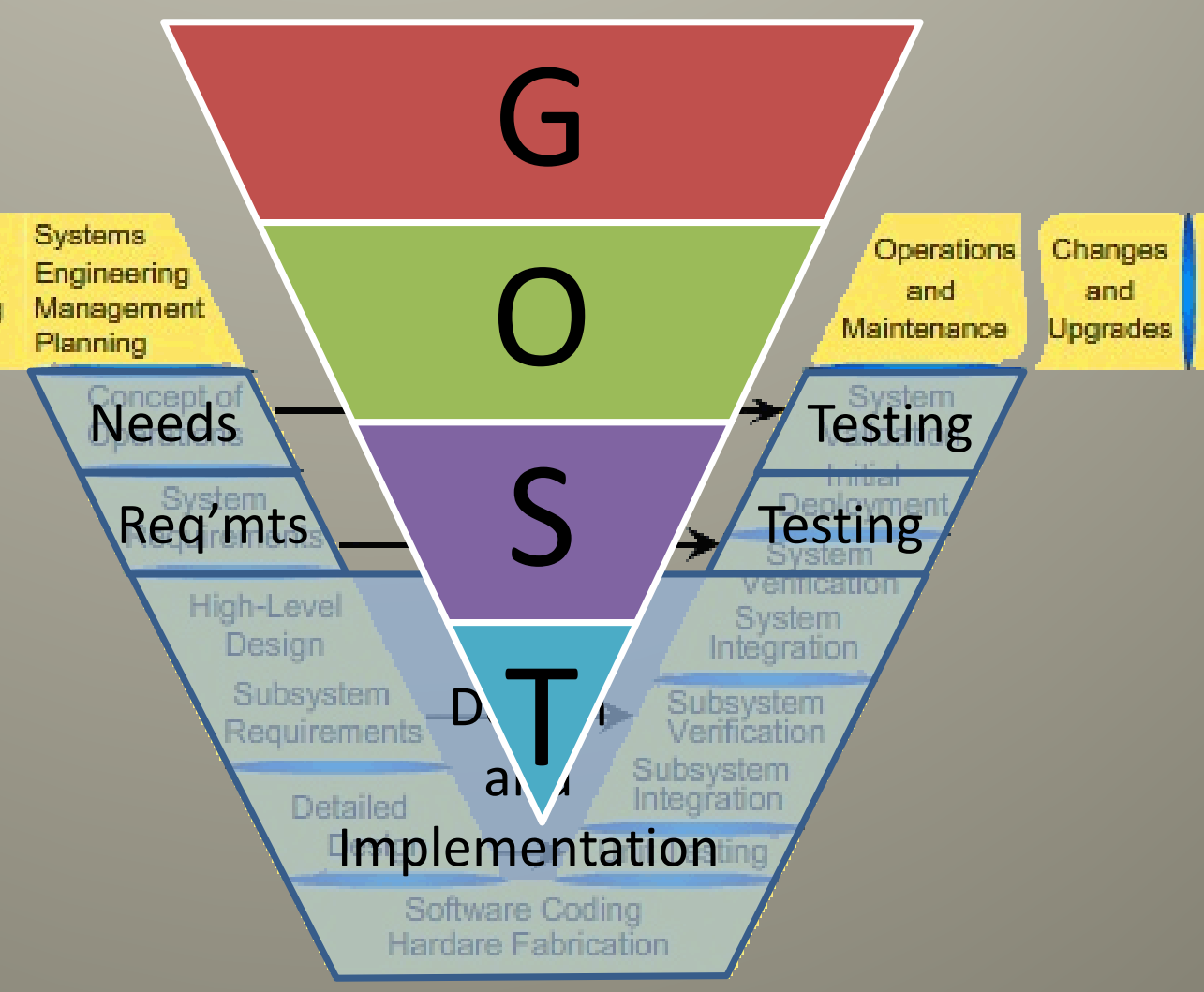




\section{WWII Analogy - Eisenhower}

- How fast Germans moved armies during WWII

- America embroiled in the Red Scare

- Post war prosperity presented an opportunity 
How would we use a new roadway network

- Move armies quickly

- Move people, goods \& services efficiently

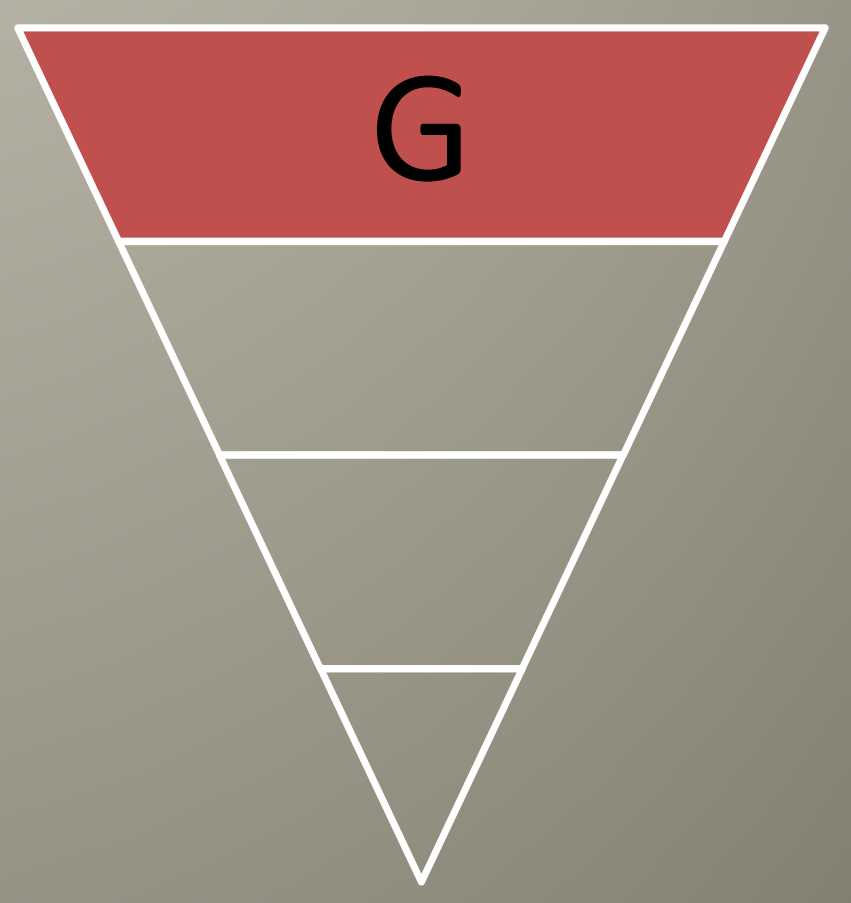




\section{What slows armies down?}

NEEDS

- Intersections

- Narrow roads

- Tight curves

- Incomplete network

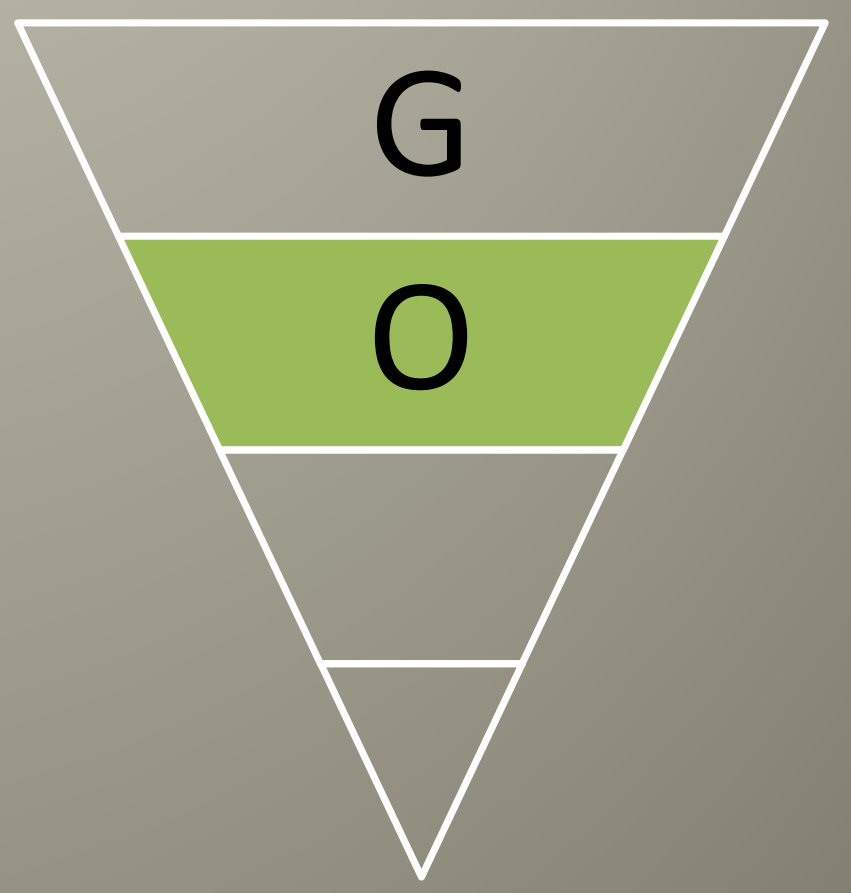




\section{High Level Requirements}

- Limited access

- Wide lanes with shoulders

- Divided highway

- High design speed

- Comprehensive network

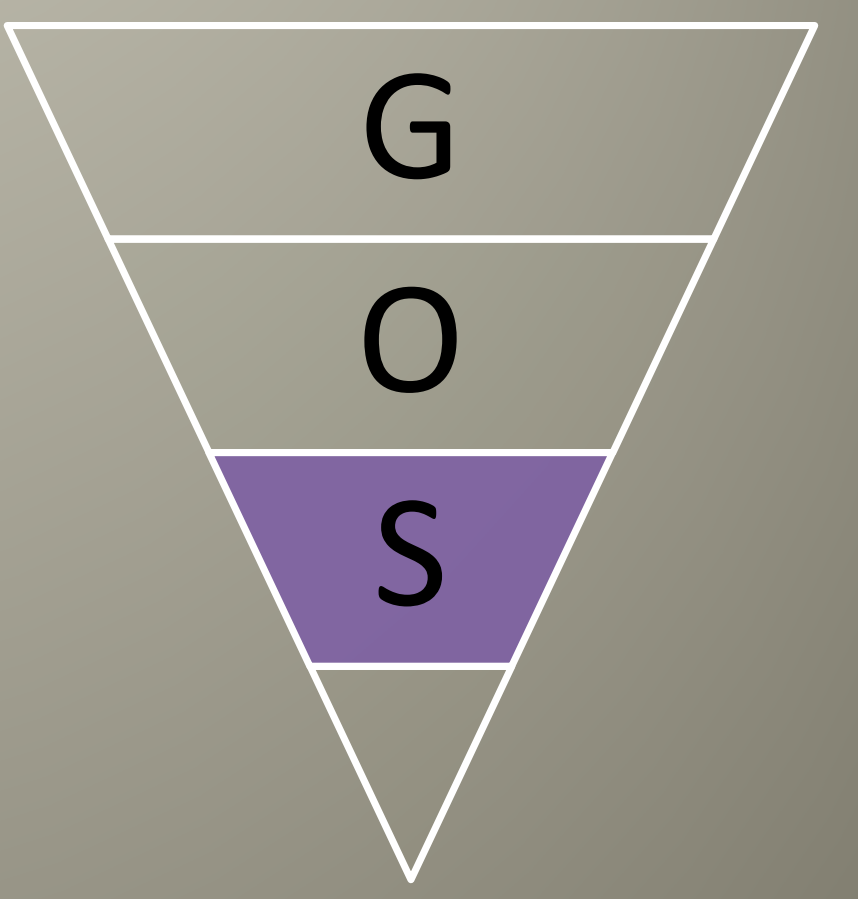




\section{Detailed Requirements}

- The highway shall have no at-grade crossings.

- The highway shall separate the two directions of travel.

- The highway shall accommodate vehicles traveling at $70 \mathrm{mph}$.

- The highway shall have $12^{\prime}$ foot lanes.

- The highway shall have vertical clearance of $16.5^{\prime}$.

- The highway shall have maximum grade of $6 \%$.

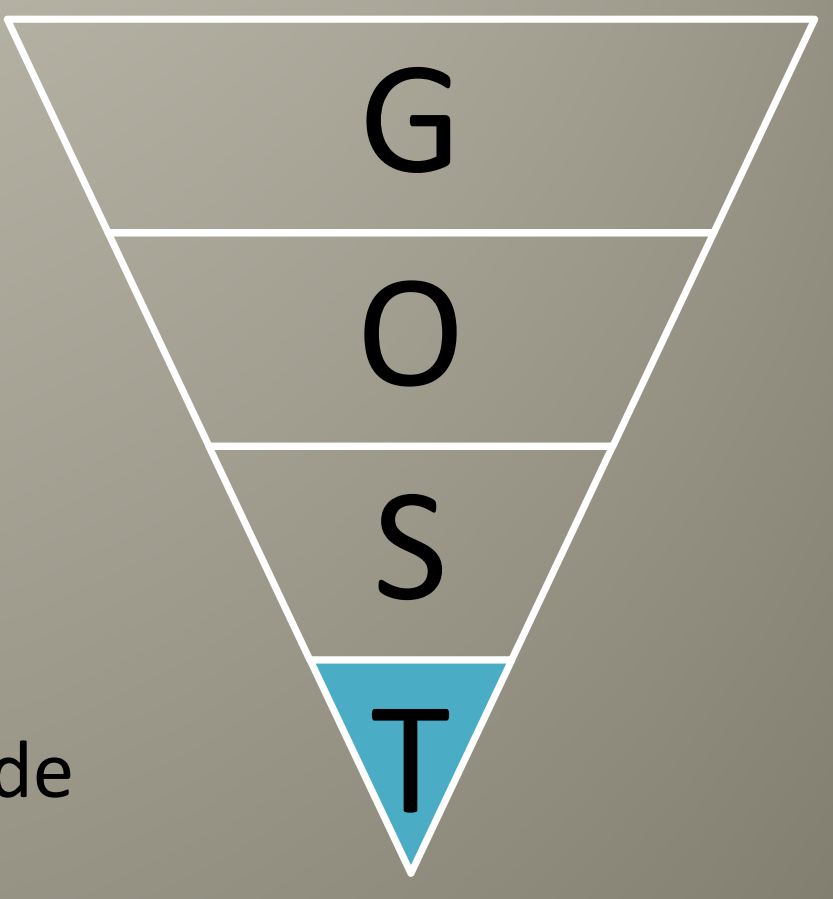

- The highway network should comprise principal east-west and north-south routes. 
- Did Eisenhower know anything about building roads?

- Do road builders know anything about moving armies?

- Do they need to? 


\section{Did the road get built right?}


Did we build the right roads? 


\section{Systems Engineering}

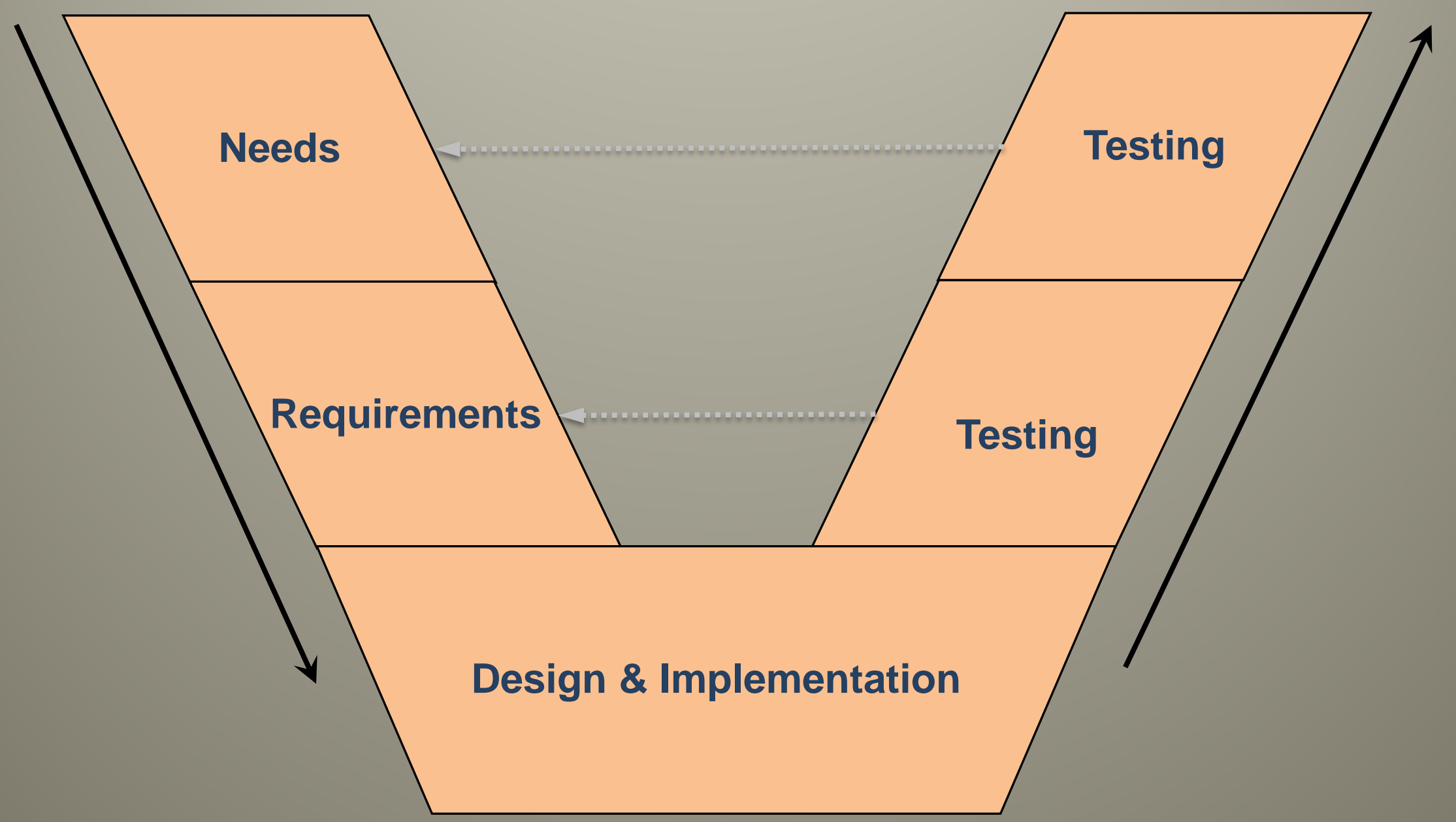




\section{Mitigating Risk}

- Designing the roads incorrectly

- Designing the wrong roads

- Spending too much

- Taking too long to build

- Responding to challenges 


\section{Purpose of SE Model Documents}

- Evaluate need for Adaptive Control

- Limitations of Existing System

- Objectives \& Needs for Improved System

- Requirements to guide procurement and acceptance testing

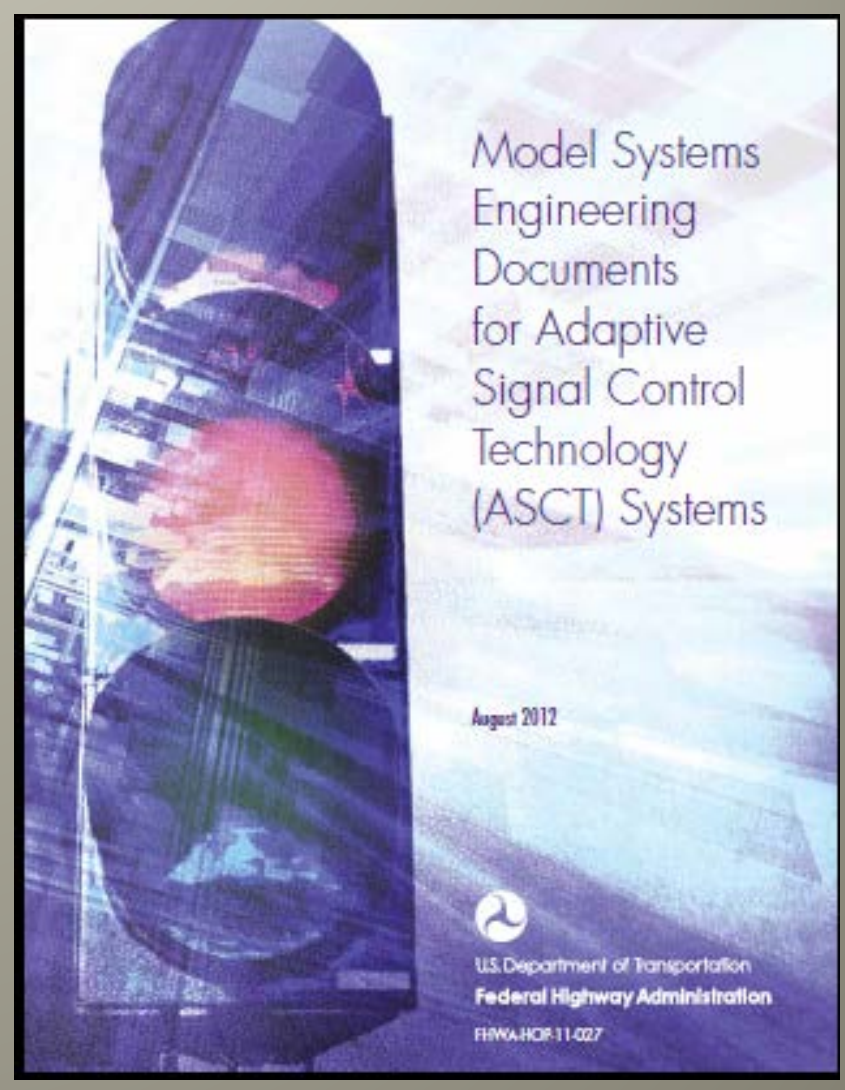

- Basis for validation testing 


\section{Model Document Process}

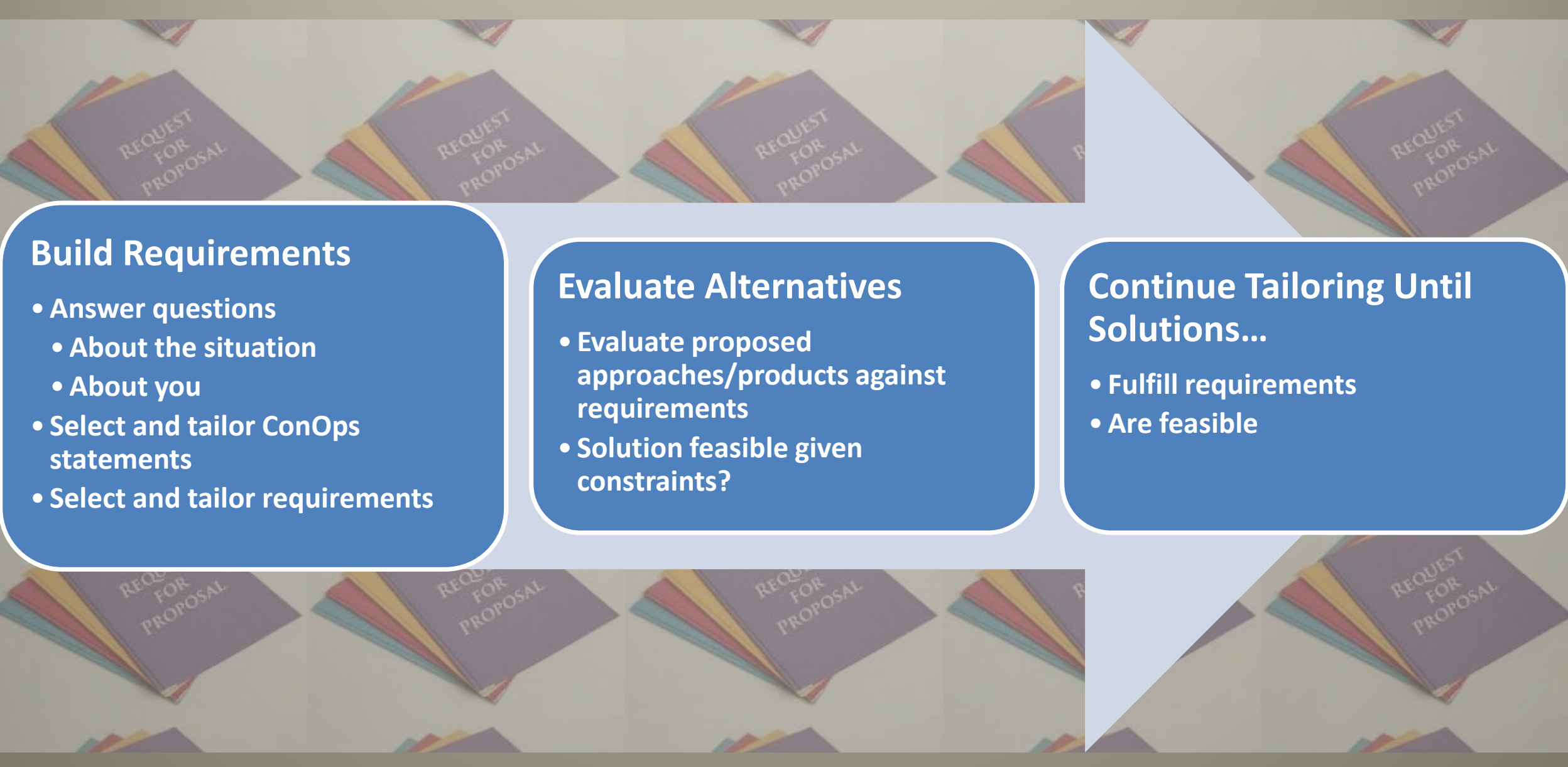




\section{US Implementation 2015}

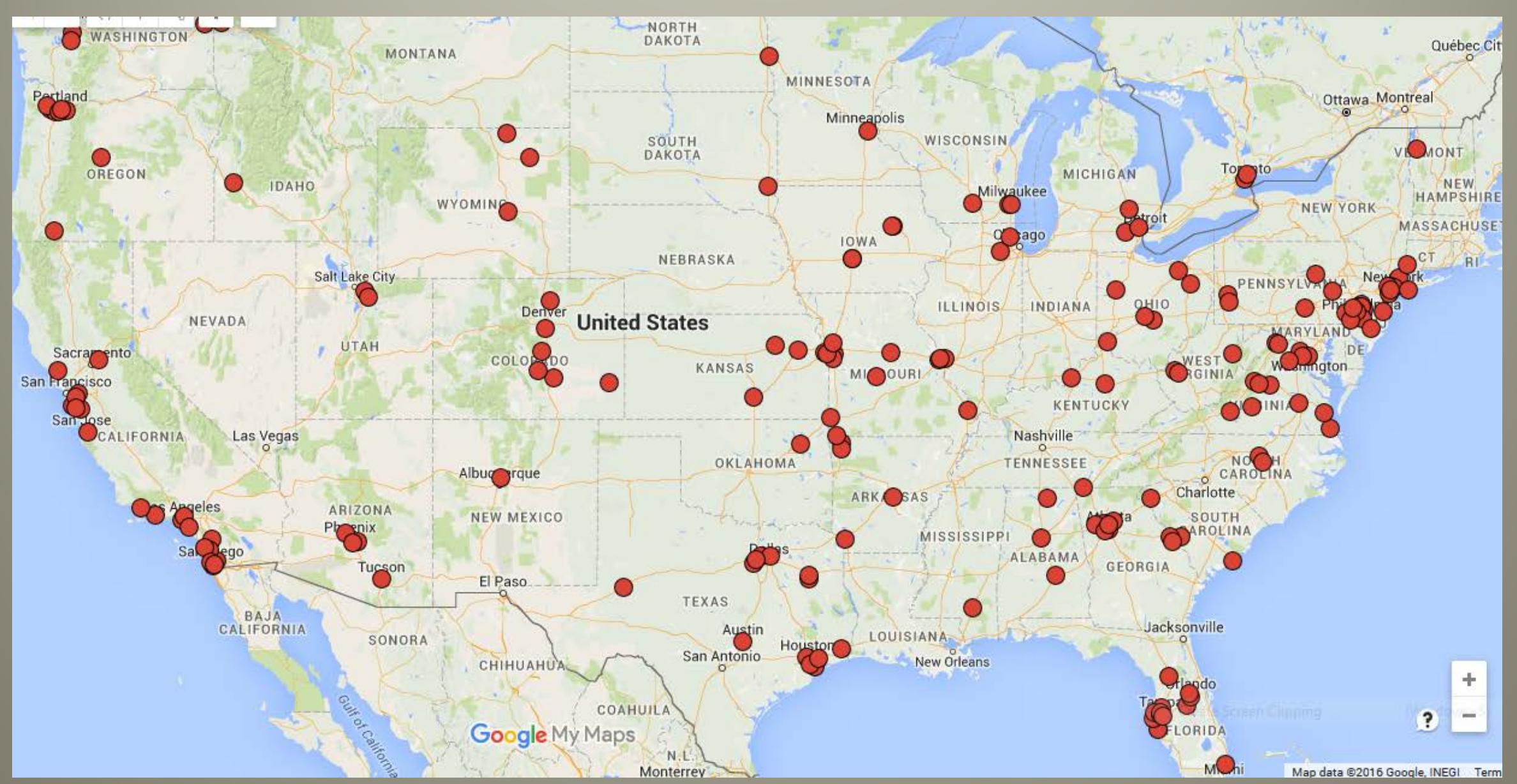




\section{Application of Systems Engineering Before and After MSED}

$62 \%$

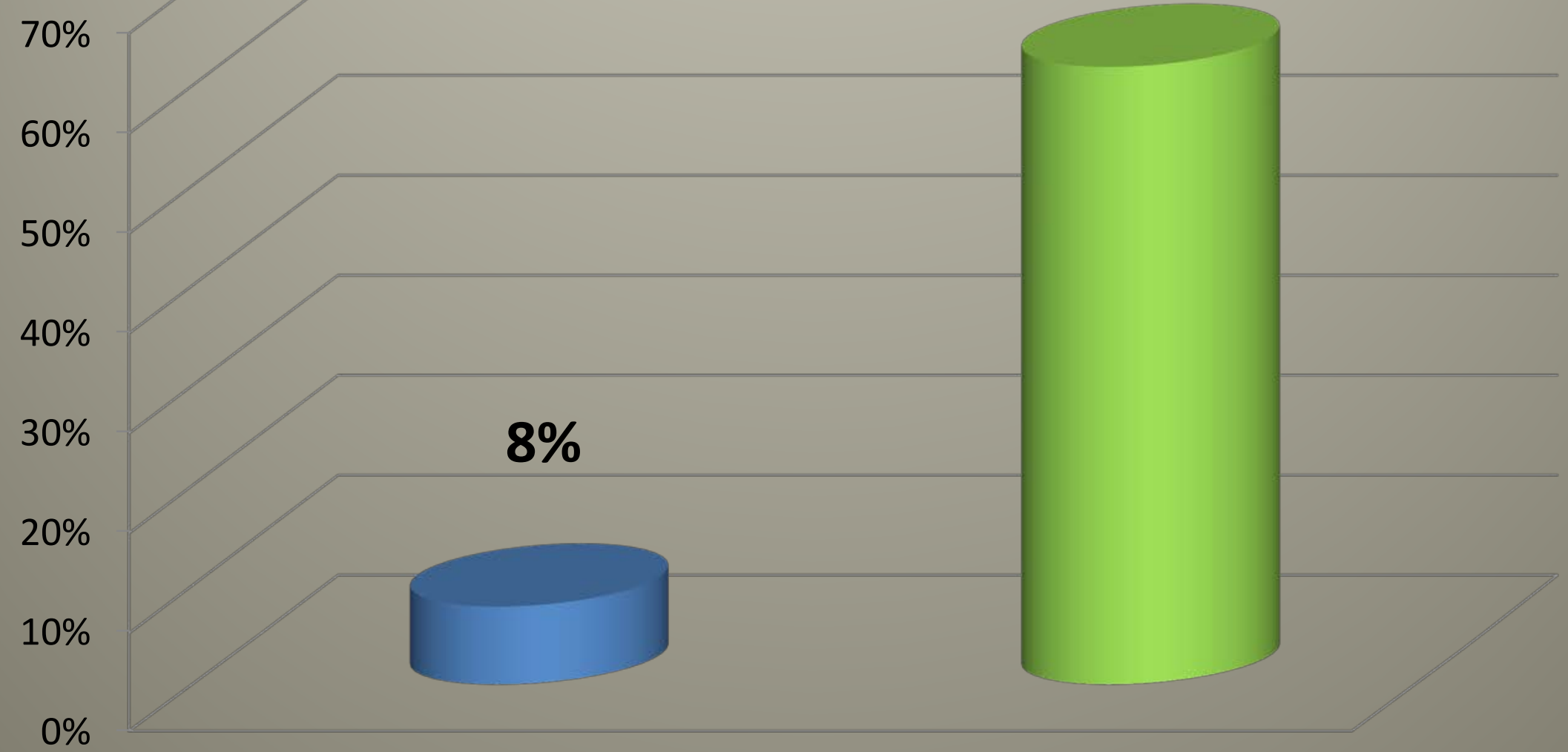




\section{Systems Engineering at all Phases}

- Clarifies the Goals and

- Research Objectives

- Identifies Performance

- Technology Measures

- People

- Provides Context for

- Implementation

Constraints

- Address Risks

- Conforms to Federal Regulation

- Competitive Procurement

- Manages Cost 


\section{Application to Automated Traffic Signal Performance Measures}

- Systems Engineering is GIVEN

- Goals, Objectives (NEEDS)

- Validate research outcomes

- Fuels Innovation

- Requirements

- Address risks

- Support acceptance testing

- Leverage funding opportunities

- Ped/Bike

- Transit

- Connected Vehicles, Integrated Corridor

- Collaboration and Competition help the process

- Don't hide failures 


\section{Good Basic Service (GBS) Model}

Infrastructure Reliability

\section{Principles}

Clear objectives

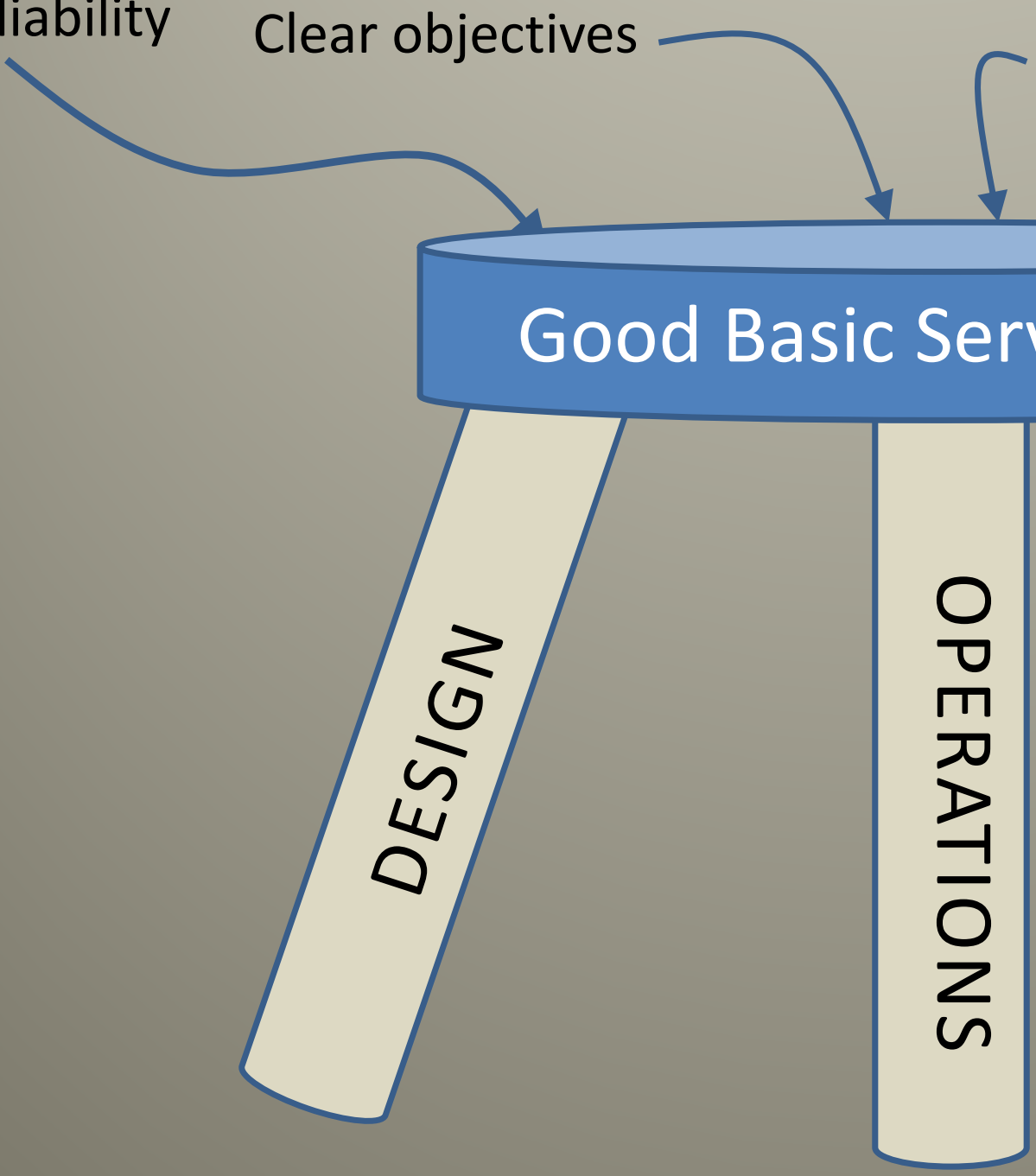

Staff

Development

Measures 


\section{Leg Segments and Composition}

Good Basic Service (GBS)

Local

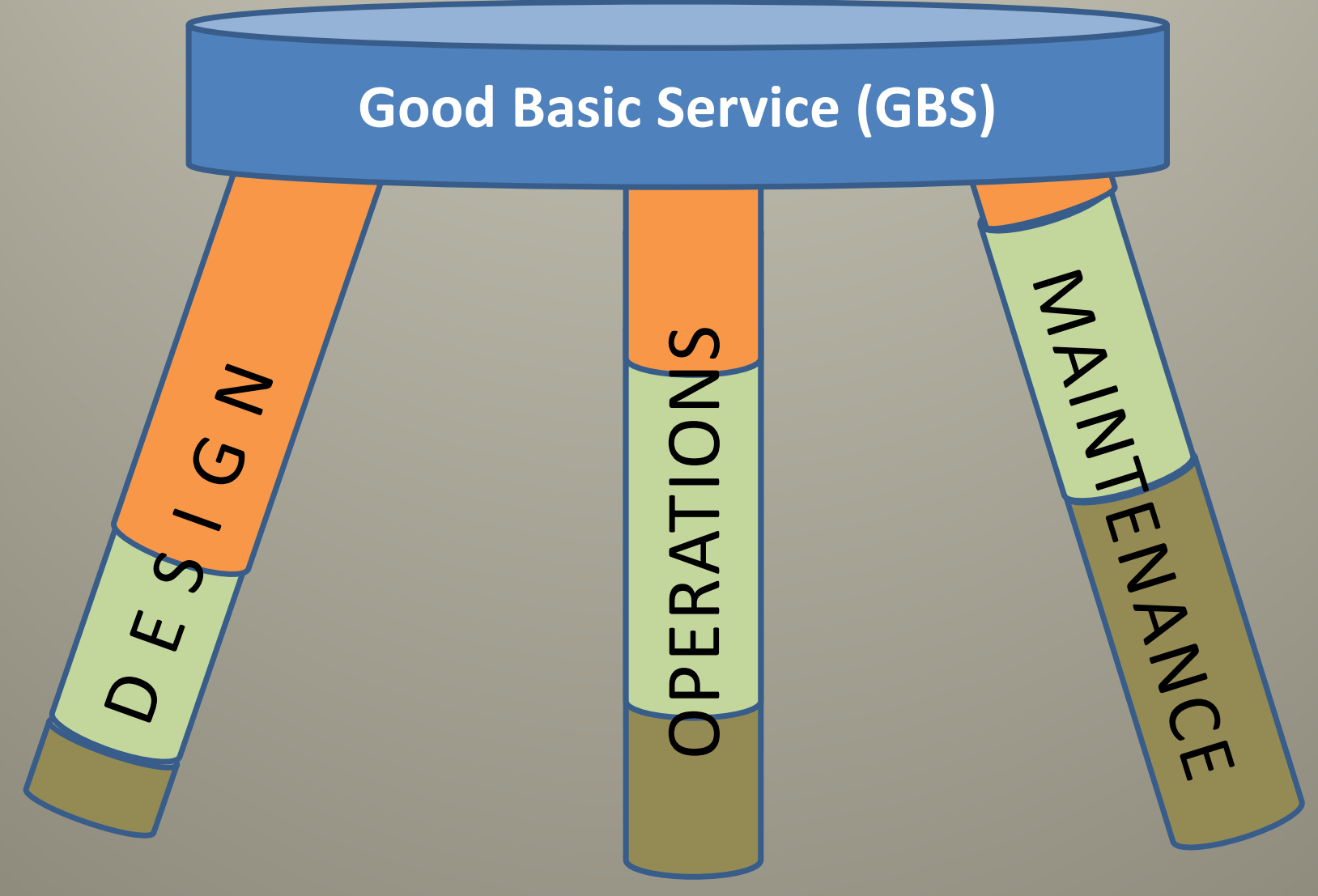

$\longrightarrow$ State

Federal 


\section{Summary}

- Organizational and Institutional Issues must be acknowledged

- A Systematic process is critical to linking Research to Implementation and can drive innovation

- Innovators and Early Adopters must be leveraged to demonstrate benefits

- The majority of the market is risks averse

- Meaningful Performance Measurement

- Top Down \& Bottom Up approaches are key 


\section{Every Day Counts 4}

- Request For Information (RFI)

- Federal Register Notice

- Innovation of Interest

- Automated Traffic Signal Performance Measurement System

Every Day Counts Better, Faster, Smarter

- Submit responses by email to everydaycounts@dot.gov Deadline: January 31, 2016

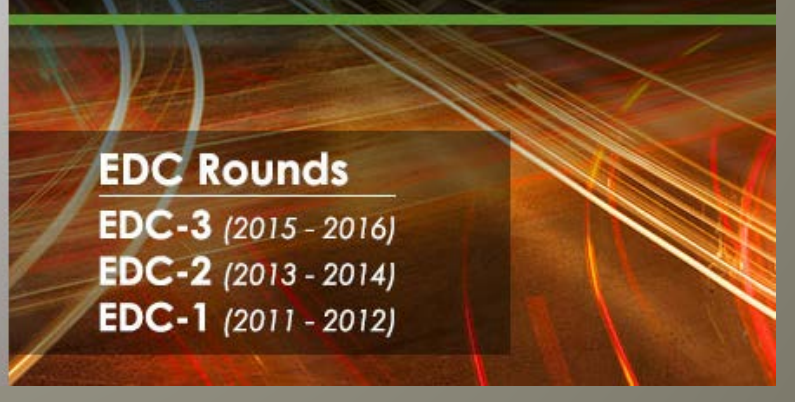


